\title{
Whose Country to Defend?: The Chicano Soldier on Stage
}

\section{Zack Whitman Gill}

As the debate on the role of Mexicans in the US persists, and while the number of Chicanos serving and dying in Iraq and Afghanistan escalates, it is essential that Chicana/os expose the hegemonic erasure of their role in defining and defending any notion of "America." Chicanos/as have a long history of sacrificing their lives in service to the US only to be denied access to the land that was once theirs and suffer their contribution erased from the historical narrative; a combination of politics, willing blindness, and outright racism ensures that the hyphen that separates Mexican and American remains a firm border. However, five plays from the relatively brief history of contemporary Chicano drama, Luis Valdez's The Shrunken Head of Pancho Villa and Dark Root of a Scream, El Teatro Campesino's Vietnam Campesino and Soldado razo, and Culture Clash's Chavez Ravine, specifically foreground the figure of the soldier to dramatize the hypocrisy wherein "America" is defined against Chicanos who in turn are rejected as only, at best, Mexican-American. Both in the plays, and by extension in actuality, these soldiers fight for a society that actively disenfranchises them, thereby allowing their colonization and marginalization to continue. In the process, they embody the conservative and self-destructive mentality inherent to the Mexican-American identity offered by a colonizing society invested in exploiting and distancing itself from the Chicano/a community. In response, each play theatricalizes the liberating and political potential of self-identifying as Chicano/a, embracing its inherent politicized stance and Aztec and Mayan mythos as a fundamental aspect of identity in direct opposition to the foundations of dominant culture and military service. Reading these plays against Homi K. Bhabha's notion of mimicry and Marvin Carlson's concept of ghosting, this essay argues that the current debate on immigration reinforces the need for Chicano/a playwrights to exploit the figure of the soldier to not only ground a definition of who 
they are, but to stress the importance of Chicanas/os maintaining their own, separate identity.

All five of these plays deal specifically with questions of identity, social and political justice, and the existential realities of life as a person of Mexican descent living in the United States during or immediately following war. Both The Shrunken Head of Pancho Villa and Chavez Ravine, although written almost 40 years apart, utilize the aftermath of World War II to dramatize the difficulties facing Chicano families while impressing the importance of resisting societal and government attempts to suppress activism. In the case of Shrunken Head, a family "in crisis" living in the barrio highlights, via "distorted or stereotypical" means, the political, economic, historical, and cultural challenges and strengths of Chicanos (Huerta, Chicano Theater 49). Using symbolic and larger than life imagery, Shrunken Head tracks the unraveling of a family - complete with an alcoholic father, two sons (one a vato loco son and another a vendido), and the giant, grotesque head of Pancho Villa posing as a third son — as each member struggles with their identity and place in society. Chavez Ravine utilizes the events surrounding the forced eviction of the residents of Chavez Ravine, first for federal housing and eventually in order to build Dodger Stadium in the early 1950 s, to dramatize the strength of community at the heart of the Chicano movement. Focusing on the narrators, WWII veteran Henry Ruiz and his activist sister Maria, the play works to recover a seemingly erased history of marginalization and outright corruption that tears apart the family and community alike. The two Teatro Campesino actos, Vietnam Campesino and Soldado razo, and the mito, Dark Root of a Scream, all directly confront the Vietnam War, the draft and its economic disparities, and the political and social climate of the early 1970s. In the Campesino's tradition of using satire, transparent bias, simple solutions with obvious heroes and villains, Brechtian techniques including signs and direct audience address, and short, bilingual plots, Vietnam Campesino follows Hijo and his family of farm workers as they struggle against their contractor, grower, and the government, while Soldado razo follows young Johnny as he goes off to war in order to impress his family and girlfriend only to die in action. Dark Root of a Scream, likewise, recounts the life of Indio, already killed in Vietnam, and culminates in a call to embrace indigenous mythos and Chicano ideals going forth - the howl of the mito's title. As Jorge Huerta argues for Shrunken Head, but applicable to the rest, "by focusing on characters who deny their heritage and attempt to blend into the allegorical melting pot," all of these plays "demonstrate 
what the Chicano should not be and indicate positive alternatives to such behavior" (Chicano Theater 47).

There is a significant distinction between the terms MexicanAmerican and Chicano. Indeed, "[m]ore often than not, 'Chicano' is used as a political label, a badge which connotes a sense of otherness. Just as there are biological and cultural aspects to being a Mexican-American, it must be understood that not all Mexican Americans call themselves Chicano regardless of whether or not they have felt marginalized in this society" (Huerta, Looking for the Magic 37). Self-identifying as Chicano is an inherently political stance, as to be Chicano is to reject the crusade to "fit in" and "naturalize" into US society and to instead celebrate indigenous culture and mythos, purposefully problematizing the notion of a melting pot or a singular American identity. At the same time, Chicanos actively dissociate from a Mexican identity as well, insisting on their unique culture as a result of living in the US. Neither Mexican nor "American," Chicano/as exist betwixt and between. Juan BruceNovoa states in reference to Chicano literature that

Chicanos [...] choose to be other than US American or Mexican. They reject the chaos of deculturation, but in the act of defining themselves they discover a non-Mexican identity as well. [...] To attempt to eliminate completely one or the other is to cease to be Chicano. [...] Chicanismo is the product/producer of ongoing synthesis, continually drawing from what seems to outsiders to be opposing cultural elements. Therefore, the literature proposes an alternative, an "inter" space for a new ethnic identity to exist. (31) Bruce-Novoa's statement at once seems to reaffirm and contradict the power granted the hyphenated identity in Jennifer DeVere Brody's "Hyphen Nations." Brody examines how the hyphen has been used as an identity tool for "resisting dominant strategies of erasure and marginalization" (159), specifically granting the hyphen a power to performatively disrupt the norm:

The hyphen performs - it is never neutral or natural. Indeed, by performing the mid-point between often conflicting categories, hyphens occupy 'impossible' positions. [...] Hyphens are problematic because they cannot stand alone: in fact, they do not 'stand' at all, rather, they mark a de-centered if central position that perpetually presents readers with a neither/nor proposition. Hyphens locate intermediate, often invisible, and always shifting spaces between supposedly oppositional binary structures. (149) 
On the one hand, by occupying the space between Mexican and American and rejecting their opposing pull, Chicanos certainly complicate the notion of an all-encompassing "American" identity by disrupting attempts at categorization. But at the same time, Chicanos choose to distance themselves from the performative hyphen, rejecting that "impossible position" for a wholly new space; indeed, Chicanos see Mexican-Americans as opting to reinforce their marginalization through their attachment to the two halves of their identity. Ultimately, it has been Chicanos, not Mexican-Americans, who locate their identity in difference and contestation and resist marginalization. Just so, in each of these plays it is the Chicano characters that serve as the sources of resistance to exploitation, racism, and oppression, while the characters that either overtly or implicitly identify as Mexican-American consistently attempt to erase the first and celebrate the second part of that hyphen.

The continued insistence by the US government that Mexicans in the US be legal, learn English, and abandon their culture and history for the sake of citizenship and acceptance, yet all the while being considered apart from some imagined normative identity known as American, exemplifies the essentially colonial relationship and the process of mimicry at work between the two. As Homi K. Bhabha outlines in "Of Mimicry and Man: The Ambivalence of Colonial Discourse," mimicry demands that the colonized subject attempt the impossible, simultaneously attempting to mirror the dominant while constantly being placed in a standing that negates any such efforts. For Bhabha, a driving element of colonial situations is the split between the colonizing desire to "normalize" colonial subjects and endow them with the gift of knowledge and culture, and the fear that these gifts will impede the concomitant desire to maintain power. The result is that "the discourse of mimicry is constructed around an ambivalence: in order to be effective, mimicry must continually produce its slippage, its excess, its difference" (86). The colonized subject can only remain "almost white but not quite." Through a complex process of political, economic, and social discourses, the dominant fashion the colonized to be an object against which they can define themselves, an other in need of the assimilating hand of the white savior; at the same time, the colonizer shapes the colonized to be "inappropriate" for integration, since the very otherness of the colonial subject prevents him or her from being anything but different, even ever so slightly, from the constructed norm. The ambivalence of mimicry is the impossible position of DeVere Brody's hyphen, and so identifying as 
Mexican-American is self-marginalizing, positioning the subject against some imaginary a-priori identity, as if there was any such thing as an American. The Mexican-American must always face his or her once-removed nature, always something other, more Mexican than American. Asked to fit into a homogenizing image of the colonizer's creation, the darker subject cannot, and is thereby always already perpetuating his or her otherness. Thus, rejecting the problematic and self-debasing term Mexican-American, Chicanos have celebrated their hyphenated identity without the hyphen, choosing to resist the taxonomical gift of hegemonic US society altogether, that normalizing and marginalizing term American.

Perhaps the mimicry at work in identifying as Mexican-American can best be seen within the context of military service. There can seemingly be no greater declaration of love of country or more ideal image of national identity than serving in the armed forces, offering a life in sacrifice to the preservation of the ideals and sovereignty of the state. To fight, and especially to die, for the country, wearing the uniform of the country, in the service of the country, surely guarantees the utmost respect and reverence, to say nothing of full membership into society. Indeed, the US has consistently targeted immigrant populations for military service in exchange for promises of citizenship. That shortened naturalization periods are still used as incentive for immigrants to enlist demonstrates the extent to which military service remains a major tool of mimicry by the government. ${ }^{1}$ By allowing non-citizens the chance to become citizens quicker in exchange for military service and possibly their lives or limbs, but often at the same time segregating them or erasing their contribution from collective memory, the partial presence of the colonial object is assured; the foreign national soldier is thanked for his or her service and then told s/he isn't wanted anymore. The United States has a long history of accepting the service of its disenfranchised populations in times of war yet turning its back on them as soon as the war ends: AfricanAmericans returned home from World War I only to once again face Jim Crow segregation; Japanese-Americans fought in the most decorated World War II units ${ }^{2}$ only to face stigmatization as Japanese enemies or to hear the accounts of life in internment camps; and Chicanos have earned more Medals of Honor, twelve, than any other demographic group in the US per capita, but have been largely erased from the historical narrative, as the controversy over the absence of Chicanos in Ken Burn's World War II documentary The War demonstrated. ${ }^{3}$ 
Evidently, not even military service comes with a guarantee of respect or even acknowledgement of a status as an American - the hegemonic gap between the colonizer and the colonized maintains even when those colonized have fought and died to preserve the very state that oppresses them. Bhabha terms this ultimately fear-based division "menace," the opposite end of mimicry. He writes that the cycle of mimicry and menace, from Mexican to American soldier and back again, repeats itself and remains, theorizing that "the ambivalence of colonial authority repeatedly turns from mimicry - a difference that is almost nothing but not quite - to menace - a difference that is almost total but not quite" (91). When Chicano soldiers all too closely mimic the dominant's self-image and threaten to collapse the entire hierarchy, the response is to deny any similarity between the two. So how can Chicanos/ as, or any something-American, ever hope to move beyond this colonial mimetic condition?

One tactic utilized by Chicanos has been to employ theatre to point out this inherent hypocrisy through foregrounding the fate of the MexicanAmerican soldier and offering an alternative positive Chicano with which to identify. The effectiveness of using the soldier to make this argument stems from the position of the soldier in relation to the other characters the servicemen are shown to be vendidos, sell-outs who choose to abandon their cultural identity for little return and who stand in stark contrast to the Chicano/a characters who actively pursue a life of fighting for social justice. The plays utilize a three-part process, simultaneously drawing attention to a history of military service, rejecting that history by highlighting the problems inherent to embracing a society that actively exploits and rejects minorities, and offering a stronger, more attractive identity in the form of the Chicano/a community. The first two parts of this process consist of rewriting and celebrating the narrative of US history to include the role of Chicanos willingly fighting for the nation, only to in the end reject it. This can be seen to fit into what WB Worthen terms "dialectical representation," that is, using "the recovery of an occluded history of oppression to ground an effective Chicana/o identity politics," and staging "the limits of "history' in constituting an 'authentic' ethnic subject" (103). The foregrounding and rejection of this martial past also has the effect of highlighting and collapsing the distance between mimicry and menace, forcing the focus onto the Chicano as an essential component of America, fully capable of mirroring the dominant but showing that mimicry to be self-destructive. As Worthen states in his larger study of Chicanos and history, the plays "locate identity in a specific 
history of ethnic and political struggle," using soldiers to situate Chicano/a identity firmly in a narrative from which they have been erased but which they helped write (Worthen 102). So when, in The Shrunken Head of Pancho Villa, Mingo enters for the first time "in a soldier's uniform" (162), while Henry in Chavez Ravine "appears in full military dress" (40), and first Hijo "re-enters dressed as an infantryman in battle gear," then "Johnny enters adjusting his uniform" in Vietnam Campesino and Soldado razo, respectively $(116,121)$, the plays visually and sartorially highlight the fact of Chicano service. In addition, they make specific reference to their and other people's pride in serving "their" country, reinforcing for the audience that Chicanos not only served, but did so with the same community pride and support as the rest of "America." For example, in Chavez Ravine, Father Tommy tells Henry, "Welcome home, son. We're all real proud of you," to which Henry responds, "it was an honor to serve my country, sir" (41).

Each play foregrounds the impact of having a Chicano walk on stage in uniform, forcing the audience to contend with the layers of memory and meaning activated by the sartorial specter, the ghost of American soldiers past. In The Haunted Stage, Marvin Carlson describes the effect of such "ghosting," which "presents the identical thing they [the audience] have encountered before, although now in a somewhat different context. Thus, a recognition not of similarity, as in genre, but of identity becomes a part of the reception process" (7). When the audience sees a US soldier's uniform on stage, they cannot but immediately identify it with the entire range of associations it invokes, both onstage and off, so that while the body in that uniform may not be familiar, it is an American soldier they see. This is particularly effective in the theatre, which, as Carlson theorizes, "is the repository of cultural memory, but, like the memory of each individual, it is also subject to continual adjustment and modification as the memory is recalled in new circumstances and contexts. The present experience is always ghosted by previous experiences and associations while these ghosts are simultaneously shifted and modified by the process of recycling and recollection" (2). By visually and aurally forcing the audience to tap into the repository of associations that place the soldier on a pedestal of "Americanness," and then to connect Chicanos to American soldiers and therefore link Chicano/a identity as fundamentally part of an American identity, the plays attempt to ensure that Chicano soldiers enter into the cultural memory of the American soldier. Chicanos can therefore not only reflect the idealized image of dominant society, but become a fundamental part of any conception of that society. By 
working to modify the historical narrative to include Chicanos, these soldiers collapse the distance between the ends of "resemblance and menace" that Bhabha links to the "partial presence" of the colonized due to the ambivalent "almost the same, but not quite" nature of mimicry. Bhabha explains that "the menace of mimicry is its double vision which in disclosing the ambivalence of colonial discourse also disrupts its authority. And it is a double vision that is a result of what I've described as the partial representation/recognition of the colonial object" (88). How can someone fighting in the name and image of the United States possibly threaten it?

But this dramatic celebration of the Chicano soldier is not simply to prove that they are citizens too, placing military service as a purely positive option and legacy. Indeed, the playwrights specifically position this identity as the wrong path for Chicanas/os to take, asking why they should desire and fight for a culture that actively ignores their historical contributions. In order to challenge the cultural misrepresentation at work in the process of mimicry and break free of its colonial cycle, it is necessary to uncover this occluded history and forcefully demonstrate the equivalence of the colonized subject, but it is also essential to simultaneously represent this history as an undesirable imago. Worthen argues that "although Chicana/o literature may be 'a literature marked by historicity, wherein representation is not problematic,' Chicano/a history plays seem to question the relationship between history and representation, and the uses of history in the fashioning of a Chicana/o subject, Chicano/a agency" (110). So while the three plays focus on the contributions of Chicano soldiers, they also foreground these characters not as Chicanos, but as Mexican-Americans.

Each play clearly positions the choice of military service and the desire to mimic the dominant culture as diametrically opposed to the best interests of Chicanas/os and at odds with the very nature of identifying as such. In The Shrunken Head of Pancho Villa, when the oldest son Mingo returns from war he progresses from desiring to improve the station of his entire family to eventually simply abandoning them and their culture to become Mr. Sunday, the English-language translation of his first name, Domingo. The direct implication, reinforced throughout, is that serving in the military brainwashed and whitewashed Mingo. As the play progresses, Mingo erases more and more of his personal history in order to pass: at first Mingo is unable to remember his headless brother Belarmino, "Brother? I don't remember no other brother;" he then moves to forgetting his sister Lupe, "I don't have a sister;" soon after Mingo denies he is even related to his family, "Negra? Not 
my sister, boy. You trying to be funny? I just room here" $(165,198)$. As he positions himself further from his Chicano heritage and performs Caucasian, Mingo proves himself the ultimate vendido and the embodiment of Bhabha's mimicry, wiping out his culture in a mirroring of the way Chicanos have been erased from the US narrative. When he first arrives home, Mingo displays his new car, a good old "American" Chevrolet, and immediately marks himself as distinct and apart from his family, exclaiming "you know what's wrong with you people? You're all defeated" (164). The emphasis on "you people" reflects the self-hatred that characterizes Mingo throughout, as he constantly debases Chicano culture and commodities, offering to move the whole family out of "this stinking barrio" and into "Prune Blossom Acres," a middle class development situated on the very land on which his parents used to work as farm laborers (171). Perhaps Mingo's betrayal is best exemplified when he becomes a contractor - the liaison between the white farm owners and the workers - and actively exploits Chicanas/os and their labor for his own means. In a final act of betrayal, Mingo turns his brother Joaquin in to the police for robbing a grocery store to give food to the poorer Chicanas/ os exploited by Mingo himself. This process of attempting to be as close to dominant white society as possible no matter the cost is posited as a direct result of his military service - it is only after he returns from war and enters the play that Mingo begins this transformation, and it is through his status as a war veteran that he is able to achieve it, using the "G.I. bill [to] foot the bill" (191). Similarly, Henry in Chavez Ravine returns from World War II seduced by the pull of dominant white society and therefore abandons his own culture and community. Henry hints at his eventual shift when in response to his mother's offer of homemade tortillas and menudo, he responds with "I hate menudo. [...] I'll just get a French Dip at Phillipe's" (42). Henry later complains that the house in Chavez Ravine that his mother gave to him "is too small," and when housing officials put pressure on the barrio residents to sell their houses, Henry is one of the first to consent. Henry's military service functions as a direct cause of the betrayal of his roots, as he argues, "[i]t's a free country. [...] I'm taking my GI Bill and the city dough and never looking back. I'm gonna give my kids more than footprints in the dirt and chicken shacks. It's a goddamned slum up here" (46). Henry literally sells out , choosing to embrace a culture shown to be actively conspiring against the interests of Chicanos/as, and once again, it is his military service that both enables and motivates this choice. 
While not serving voluntarily but instead drafted, the two soldiers of the actos Vietnam Campesino and Soldado razo, Hijo and Johnny respectively, betray their own people and, like Mingo and Henry, highlight how no matter how hard they might try, at best the colonized can only mimic imperfectly. In Vietnam Campesino, Hijo cannot escape the lure of El Draft, "a tall figure with a death mask and an American flag for a shroud," who literally reels Hijo in, miming a fishing rod and reel; on the other hand, when El Draft tries to hook Little Butt, the Anglo farm owner's son, General Defense steps in the way, yelling "[w] hat's the matter with you, Draft? Haven't I told you to stick to the minorities?" (109). Having been fully indoctrinated into the military, Hijo is ordered to burn down a Vietnamese farm worker's village; as he willingly completes his task, the Vietnamese shoot him in the back, killing him. The message is clear: military service not only kills Hijo, and by extension all Chicanos (Hijo means, simply, son), but perverts their relations to the world and robs the movement of its future - Hijo is forced to attack disenfranchised people in very much the same situation as his family, played, of course, by Chicanos. The acto intentionally highlights the similarities between the Mexican and Vietnamese, describing both as "campesinos," and even having Hijo, when ordered to "burn the house of these farmworkers," initially approach his parents before they "hold up a paper cut out of a small labor camp shack" and "wave at him." Corrected by General Butt, he willingly betrays the principles for which he once stood and "burns the Vietnamese shack" (116). At the end of the acto, Hijo returns posthumously "with blood on his forehead," reminding the audience that while Chicanos are dying, the growers are getting rich, emphasizing the degree to which military service doesn't solve problems, but creates them (119).

In Soldado razo, Johnny justifies his decision to go to Vietnam as a rite of passage, a symbol of his manhood. As he voices his inner thoughts throughout the play, a main refrain is how the service increases his stature: "[h]er parents don't like me, I know. They think I'm a vago [Tr: "slacker"]. Maybe they'll feel different when I come back from Nam. Simón, el war veteran" [Tr: "Yeah, the war veteran"] (123). Similarly, Cecilia reveals that "[my parents] say he's more responsible now that he's in the service" (129). Johnny is motivated by the mistaken assumption, repeated and emphasized by Cecilia's parents, that identifying as Chicano is specifically not responsible whereas the self-effacing and mimicking stance of Mexican-American, actualized in the form of service, is the proper path. And so La Muerte, the narrator, reveals that "Johnny left for Vietnam, never to return. He didn't 
want to go and yet he did. It never crossed his mind to refuse. How could he refuse the gobierno de los Estados Unidos? [Tr: "the government of the Untied States"]. [...] Besides, who wants to go to prison" (132). La Muerte emphasizes the colonial relationship at work by slipping into Spanish, distancing the Chicanos being sent off to war from the country for which they are dying. Likewise, in his final letter home Johnny writes that "[ $t]$ hey say we have to do it to defend our country" (132), highlighting how the government only begins to allow Chicanos to be an active part of the nation at the price of their lives. Throughout these plays, the Chicano soldiers who fight in the name of the Untied States clearly stand in opposition to their own culture and heritage, either being forced to abandon their friends and families only to die, or willingly accepting a whitewashed life mimicking that which they aren't. Trying to live up to the perfect image that another culture strives for cannot but fail, and thus the Mexican-American soldier remains not quite white and not Chicano, an imperfect and unappealing imago.

Standing in counterpart to these vendido soldiers are the Chicanos who embrace their traditions, reject any attempt to conform to the colonizing demand for mimicry, and offer a positive alternative to this entrapping process. In Chavez Ravine, Henry is placed in opposition to his Chicana sister Maria, who when faced with the same difficult decisions as Henry, consistently chooses to maintain her connection to her ancestry and resist any colonizing attempt to dictate her way of life. At the end of the play, she speaks of the importance of identifying with and supporting the Chicano/a community, asking the audience:

What does the immigrant want? The immigrant doesn't want trouble, he wants to make it, he wants his little piece of land/ [...] It's true we lost, but what's important is that we helped create a culture of resistance. The struggle for Chavez Ravine prepared me for civil rights, the Farm Workers Union, my labor work with Bert Corona and the Chicana Movement. Chavez Ravine was huge for me. It made me the person I am today. (81)

Maria chooses resistance and activism over integration, embracing the history of the "sacred land," Chavez Ravine, and celebrating her refusal to emulate and mimic her exploiters (41).

In The Shrunken Head of Pancho Villa, the younger brother Joaquin purposefully pursues the opposite path as Mingo, gradually becoming more and more radical in his rejection of "American" society and eventually becoming a full-fledged revolucionario in the mold of Emiliano Zapata and 
Pancho Villa. Joaquin begins the play as a vato loco in and out of trouble with the law for petty crimes he may or may not have committed. But as Mingo evolves from Chicano into Mexican-American vendido, Joaquin follows the influence of his bodiless brother, Belarmino, who claims to be the decapitated head of Pancho Villa. While ultimately futile, whether it is challenging Mingo's exploitation of field workers or his attempt to "rob from the rich to give to the poor" which results in jail time, Joaquin's actions are always posited as for the good of the Chicano/a community. Joaquin returns from prison headless, having been "rehabilitated" and thereby stripped of his mind, the source of his Chicanidad. But while Mingo is beyond hope in his quest to be as white as possible, even the headless Joaquin is a source of power, providing the body for Belarmino to once again become the full figure of Villa and return to his people. The contrast is sharp and purposeful. As Jorge Huerta notes, "[t]he juxtaposition of the bodiless head and the headless body is clear: combine them for a complete, revolutionary man. It is the playwright's hope that the confusion he perceives in the barrio will be replaced by a political consciousness" (59). Indeed, Belarmino's line, "So don' worry, my people, because one of these days Pancho Villa will pass among you again" (207), ends the play on a note of hopeful triumph, insisting on a future grounded in chicanidad, a politicized, revolutionary mind to replace the brainwashed, frustrated but willing bodies of la raza. The only possibility of breaking free from the cycle of oppression and violence that leave young male Chicanos with only two choices, selling out or acting out, lies in embracing and celebrating the very traditions, histories, and revolutionary activism that defines being a Chicano/a.

In both Vietnam Campesino and Soldado razo, the soldiers are shown not only to betray their Chicano traditional cultures, but to actively annihilate them. As already mentioned, Hijo destroys and is destroyed by the Vietnamese who mirror his own family, and Johnny writes to his parents about his dream just before he is killed: "I dreamed I was breaking into one of the hooches. [...] I went in firing my M-16. [...] I killed three of them right away, but when I looked down it was mi 'Apa, el carnalillo and you, jefita [TR: my father, my little brother and you, mom"]. I don't know how much more I can stand. Please tell Sapo and all the vatos how it's like over here. Don't let them... BANG!" (133). The alternative to military service appears in the last play of the trilogy, Dark Root of a Scream. In this mito, the soldier nicknamed Indio is actually named Quetzalcóatl after the Meso-American feathered serpent god who abolished the sacrifice of human war prisoners. Before he 
was drafted, Indio was a Chicano activist and community leader, calling for "Chicanos to be proud of what they have - their culture, their heritage" (9). The end of the play offers perhaps the most explicit dramatization of the rejection of vendido mimicry and a plea to look inside for a resolution via a confirmation of the cultural practices and institutions of Chicanos as a source of strength and pride, not to be erased but embraced. As blood drips from Indio's coffin, his mother opens up the box to pull out "a brilliant headdress of green feathers and a cloak of Aztec design"; Lizard, having assumed the role of priest and donned the robes, quickly trades them for the Quetzalcóatl vestments, actualizing the rejection of the religion of the colonizer for their own abandoned spirituality. Then, as "drums begin to beat immediately, low and somber and increasingly loud," they pull out Indio's heart from the box, which "gives out light in the descending darkness" as the play ends (19). It is the Chicano/a corazón, the bleeding, yet radiant guiding light fed by the beliefs and strengths of its people, demanding and proclaiming that it is there that Chicanas/os must locate their identities. Chicanos continuing to be seduced by the deceptive offer of a better life and culture against their best wishes and dying in service to a nation that only half-heartedly welcomes them home literally bleeds the Chicano movement dry.

It has been quite a few years since Culture Clash wrote Chavez Ravine, and over thirty-five years since the actos and plays of Luis Valdez first appeared - much has changed without changing at all. The current immigration debate only serves to highlight just how powerful the process of continued colonization through forced mimicry remains, and how difficult it is to break free of it. Under former President [GW] Bush, the proposed immigration bill in the House of Representatives stated that only once the US had met certain border security conditions could the "new worker" program take effect; the "alien" must remain employed for five years, pay a fee, and be "pursuing English language and US history education" (H.R.1645). What is more, each person applying for citizenship must return to his or her home country at least once during the process to pay a sizeable fine, a clearly problematic requirement. As part of the attached "Strengthening American Citizenship Act of 2007," the bill allowed for a shortened residency requirement on the condition of "English fluency" and "[d]irects the Secretary [of Homeland Security] to establish an American citizenship grant program for qualified entities to provide civics, history, and English classes to promote the patriotic integration of prospective citizens" (H.R.1645). ${ }^{4}$ Similar versions of the same basic program were debated in the Senate and proposed by then 
President Bush. As conservative backlash to the bills indicates, posited in terms of border security and notions of legality, these immigrants represent a threat to the hegemony, stealing jobs and homes and, on a deeper more ambivalent level, a fear that these immigrants might mimic too well and break free from their subjugated status. Yet, according to the bills, immigrants must also be as American as possible, paying income taxes, learning English, taking civics lessons, simply to have the "right" to be "American." The ideal vision of America as put forth by those leading this debate simultaneously offers the disempowered a seemingly retainable model to follow, but is constructed in actuality as impossible to mimic.

Self-identifying as a Chicano/a in the United States not only carries with it a political stance, but a cultural one as well. To be Chicano in these plays was to embrace Aztec and Mayan mythos as a fundamental aspect of identity in direct opposition to the foundations of dominant culture, namely English and altogether bourgeois values, precisely the elements demanded by the immigration bills to be a "legal" citizen. If becoming "American" means abandoning your ancestral language, history, and culture, for "patriotic integration," then it cannot but disempower and marginalize. As debates around immigration are only increasing, ${ }^{5}$ with sides being taken and walls being built, perhaps it is time again to return to the Teatro Campesino acto, to actually get out into the barrios, camps, factories, cities, and fields populated with Mexican workers and ensure that the Chicano message is being heard by those who need it most - and what better and more pertinent example of the extent of mental colonization than the Mexican-American soldier? In this era of eternal and total global war, soldiers will continue to take on new and forceful significance in both US society and culture and on stage. It is imperative, therefore, to use this figure to highlight the hypocrisy at work in how America views the Chicano/a, at once needing them for their labor and service and to define themselves against, while at the same time rejecting any claim as American and only ever allowing them to be, at best, Mexican-American.

\section{University of California, San Diego}

\section{Notes}

Indeed, "[a]s of February 2003, there were 37,000 noncitizens serving in active duty in the US armed forces, almost 12,000 foreign nationals serving in the selected reserves, and another 8,000 
serving in the inactive National Guard and ready reserves" (Lee and Wasem). With regard to military service and naturalization lengths, the same Congressional Research Service report states, "[d]uring peacetime, noncitizens in the military may petition to naturalize after 3 years aggregate military service rather than the requisite 5 years of legal permanent residence. During periods of military hostilities, noncitizens serving in the armed forces can naturalize immediately" (Lee and Wasem).

2 The 21 Medal of Honor recipients who served in the all-Japanese $442^{\text {nd }}$ Regimental Combat Team and the 100th Infantry Battalion, later merged into the $442^{\text {nd }}$, mark the Nisei unit "the most highly decorated unit of its size in US military history (globalsecurity.org).

3 After heavy pressure, Burns did finally agree to re-edit his documentary after his initial claim that the piece was complete and additional material would be added in as a "footprint," that is, apart from the main narrative (Farhi).

4 Notice that immigration issues are couched in terms of "homeland security," a fitting example of the perception that non-citizens mimicking citizens represent a grave and direct threat to the United States.

5 It is worth noting that even with new leadership and a promise of a new direction for the country theoretically away from Bush-era policies, Candidate Obama and now President Obama has taken a remarkably similar stance to his predecessor on the topic of immigration. The President, when running for office, supported "additional personnel, infrastructure and technology on the border and at our ports of entry" in order to "preserve the integrity of our borders" (barakobama.com). Likewise, Obama vowed that only those "undocumented immigrants who are in good standing" and able "to pay a fine" and "learn English" would receive the possibility of going "to the back of the line for the opportunity to become citizens" (barakobama.com, emphasis mine).

\section{Works Cited}

“100th Battalion, 442nd Infantry.” Globalsecurity.org. 23 May 2005. 8 August 2009. $<$ http://www.globalsecurity.org/military/agency/army/100-442in.htm>.

"Immigration." Barakobama.com. Organizing for America. 8 August 2009. <http:// www.barackobama.com/issues/immigration/index_campaign.php>.

Bhabha, Homi K. "Of Mimicry and Man: The Ambivalence of Colonial Discourse." The Location of Culture. London: Routledge, 1994.

Brody, Jennifer deVere. "Hyphen-Nations." Cruising the Performative: Interventions into the Representation of Ethnicity, Nationality, and Sexuality. Ed SueEllen Case, Philip Brett, and Susan Leigh Foster. Bloomington: Indiana UP, 1995. 149-62.

Bruce-Novoa, Juan. Retro/Space: Collected Essays on Chicano Literature: Theory and History. Houston: Arte Público Press, 1990.

Carlson, Marvin. The Haunted Stage: The Theatre as Memory Machine. Ann Arbor: U of Michigan P, 2001.

Culture Clash. Chavez Ravine. American Theatre Magazine November 2003: 37-61. El Teatro Campesino. "Vietnam Campesino." Luis Valdez Early Works: Actos, Bernabé, and Pensamiento Serpentino. Houston: Arte Público Press, 1990. 98-120. 
. "Soldado Razo." Luis Valdez Early Works: Actos, Bernabé, and Pensamiento Serpentino. Houston: Arte Publico Press, 1990. 121-34.

Farhi, Paul. "Ken Burns Agrees To Expand Documentary: Inclusion of Minority WWII Service Members Follows Latino Protests." The Washington Post Online. $18^{\text {th }}$ April, 2007. 8 August 2009. <http://www.washingtonpost.com/ wp-dyn/content/article/2007/04/17/AR2007041702076_pf.html>.

Huerta, Jorge. "Looking for the Magic: Chicanos in the Mainstream." Negotiating Performance: Gender, Sexuality, and Theatricality in Latino America. Ed. Diana Taylor and Juan Villegas. Durham: Duke UP, 1994, 37-48. . Chicano Drama: Performance, Society, and Myth. Cambridge: Cambridge UP, 2000.

. Chicano Theater: Themes and Forms. Tempe: Bilingual Press/Editorial Bilingüe, 1982.

Lee, Margaret Mikyung and Wasem, Ruth Ellen. "Expedited Citizenship Through Military Service: Policy and Issues." Congressional Research Service. 30 September 2003. Federation of American Scientists. 8 August 2009. <http:// www.fas.org/sgp/crs/natsec/RL31884.pdf $>$.

United States. Cong. Senate. 110th Congress. H.R. 1645: To Provide for Comprehensive Immigration Reform, and for Other Purposes. Introduced. [introduced in the U.S. Senate; 22 March 2007]. 110 ${ }^{\text {th }}$ Congress. Open Congress, Bills. 8 August 2009. <http://www.opencongress.org/bill/110-h1645/show>.

Valdez, Luis. "The Shrunken Head of Pancho Villa." Necessary Theater: Six Plays About the ChicanoExperience. Ed. Jorge Huerta. Houston: Arte Público Press, 1989. 142-207.

. "Dark Root of a Scream." West Coast Plays 19/20. Los Angeles: California Theatre Council, 1986. 1-19.

Worthen, W. B. "Staging América: The Subject of History in Chicano/a Theatre." Theatre Journal 49.2 (May 1997): 79-98. 